\title{
Can Intelligence Overcome the Effect of Individualism on Economic Development of Regions?
}

\author{
Tian Zengrui ${ }^{1}$, Guillermo A. Buitrago ${ }^{1}$, Husam Wahdan ${ }^{1}$ \\ ${ }^{1}$ Glorious Sun Faculty of Management, Donghua University, China \\ Correspondence: Guillermo A. Buitrago, Glorious Sun Faculty of Management, Donghua University, China
}

Received: July 12, 2017

doi:10.5539/ibr.v10n9p116

\author{
Accepted: August 15, $2017 \quad$ Online Published: August 16, 2017 \\ URL: https://doi.org/10.5539/ibr.v10n9p116
}

\begin{abstract}
A clearer understanding of the causal variables of economic development is paramount object of interest for policymakers, researchers and economical analysts. Scholars share the general agreement that economic development is an important tool to alleviate poverty and foster human de velopment. In this study, we explore the role of individualism and intelligence on economic development. These results will show that both individualistic values and national IQs have positive effect on GDP per capita. Moreover, the effect of intelligence appears to be more significant in Latin America.
\end{abstract}

Keywords: individualism, intelligence, economic development, Latin America

\section{Introduction}

Economic development has played an important role in decision making in academic, political and entrepreneurial scenarios. The influence of cultural factors have been analyzed by various authors and analysts. To begin with this analysis, it is important to mention that there is general agreement that economic development is an important tool to alleviate poverty and foster human de velopment. On the other hand, despite importance of economic development, it is striking how it differs across developed and developing countries. Fig. 1 plots GDP per capita adjusted for purchasing power parity for the 2016. The highest GDP per capita in the sample is 127,522 USD in Qatar and the lowest is 698 USD in Central African Republic (CAR). Even excluding, outlier countries such as Qatar, Luxemburg, Macao, CAR, Burundi and others, GDP per capita differs significantly.

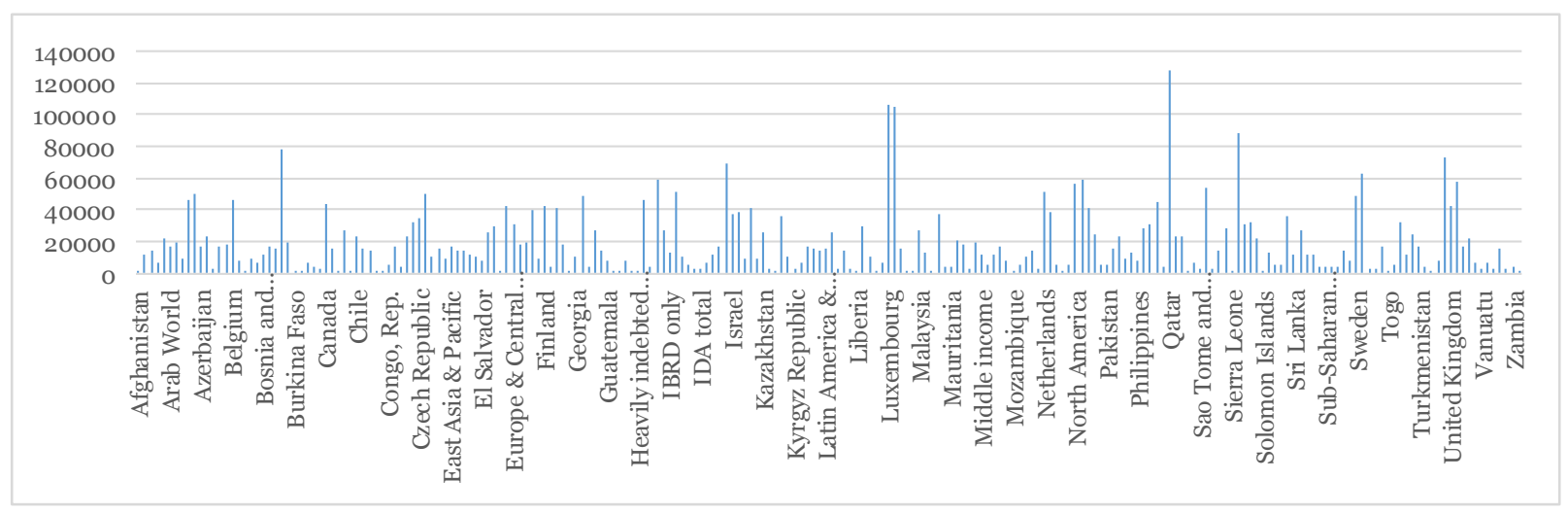

Figure 1. GDP per capita at PPP. Source: World Bank

Past studies have shown that one of the factors that may explain economic development across the globe is orientation of the society toward individualism. For example, Ball (2001) shows that individualism fosters economic development. In a similar vein, Gorodnichenko and Roland (2011 p. 57) argue that 'individualist culture attaches social status rewards to personal achievements and thus, provides not only monetary incentives for innovation but also social status rewards, leading to higher rates of innovation and economic growth'.

In an earlier study, Papamarcos and Watson (2006 p. 53) have conjectured that 'psychological independence of the individual, and the emphasis on initiative, equity and inclusiveness characteristic of individualistic cultures, would cause the individual to apply his or her labor where it would earn the highest available return'. This 
implies that at a national level, individualistic societies are more productive and thus their economic systems present higher levels on GDP per capita. Gorodnichenko and Roland (2016) using data for more than 96 countries, and instrumenting individualism with Mahalanobis distance of frequency of blood types A and B in a given country relative to the frequency of blood types A and B in the UK, show that individualism has causal effect on logged GDP per capita. Moreover, their results remain robust even when the authors instrument individualism with historical prevalence of infectious diseases.

This study explores the effect of individualism on economic development. Specifically, we focus on the effect of individualism and cognitive abilities on differences in GDP per capita within countries. These two measures of culture are very important for economic development as intelligence is the 'ability to deal with cognitive complexity, in particular, with complex information processing' (Gottfredson, 1997 p. 79). Indeed, Lynn and Vanhanen (2002) show that the correlation between cognitive abilities and GDP per capita is .66. In a follow up study, Dickerson (2006) using data from 185 countries shows that the correlation between cognitive abilities and economic development is 67.

The effects of cognitive abilities and individualism on economic development are discussed in two separate lines of research: intelligence-development literature and culture-economic growth literature. Both these strands offer alternative theoretical arguments. According to Lynn and Vanhanen (2012) '[from the] studies showing that intelligence is positively and causally related to earnings among individuals, it can be predicted that this association should also be present across nations. The earnings of nations are generally expressed as per capita income'.

Up to date, these two courses of research have stayed on separate routes. Our paper conjectures that the effects of individualism and cognitive abilities on economic development need to be researched together. While both individualism and intelligence is shown to increase GDP per capita, scholars also find that individualism moderates the effect of intelligence on happiness, thus these forces may affect each other (Stolarski et al., 2015).

We aim to contribute to the extant literature on the effects of individualism and intelligence on economic development. Our results suggest that both individualism and national IQs are positively related to logged GDP per capita. In particular, a one-point increase in national IQs is associated with nearly $7.5 \%$ increase in GDP per capita.

\section{Research Method and Data Sources}

The dependent variable in our study is GDP per capita adjusted for purchasing power parity. PPP GDP is gross domestic product converted to international dollars using purchasing power parity rates. An international dollar has the same purchasing power over GDP as the U.S. dollar has in the United States. GDP at purchaser's prices is the sum of gross value added by all resident producers in the economy plus any product taxes and minus any subsidies not included in the value of the products. It is calculated without making deductions for depreciation of fabricated assets or for depletion and degradation of natural resources. This data comes from World Bank.

Our first independent variable is individualism index. This variable is originated from Hofstede (1980) who conducted one of the most all-encompassing research on how values within job environment are formed by culture (Nikolaev \& Salahodjaev, 2017). In this study, Hofstede and co-authors carried out surveys covering more than 100,000 IBM employees across different countries. Departing from their responses for 14 'work goal' questions, they estimated individualism index for nearly 50 countries. The current dataset of Hofstede's individualism index contains data for approximately 100 countries. This index is standardized and rescaled from 0 (collectivistic society) to 100 (individualistic society).

Our second main variable of interest is intelligence. In their first work, Lynn and Vanhanen (2002) have initiated a study to explore how much national IQs can explain cross-national differences in GDP per capita. They argument was grounded on the fact that intelligence at microeconomic level as a proxy for human capital is a robust antecedent of wages and income. They collected data for 81 countries and estimated national IQ for them. In their latest work, Lynn and Vanhanen (2012) estimated national IQs for more than 192 countries. As a result, this data was successfully linked to a wide range of socio-economic outcomes. Jones and Schneider (2006) used intelligence as a proxy for human capital to explore its effect on economic growth. Using Bayesian model-averaging robustness test, they estimated 1330 regressions. Intelligence was positive and significant in $99.8 \%$ of the regressions. They conclude with a statement ' 1 point increase in a nation's average IQ is associated with a persistent $0.11 \%$ annual increase in GDP per capita' (Jones \& Schneider, 2006 p. 71). Ram (2007) augmented Lynn and Vanhanen (2012) data to Mankiw-Romer-Weil model. Using cross-country data, the author shows that intelligence is a robust factor of economic growth. Hunt and Wittman (2008) estimated the effect of national IQs on economic development across developed and developing countries. They found that intelligence 
has a significant positive relationship with GDP per capita. They assert that 'in spite of the weaknesses several of their data points Lynn and Vanhanen's empirical conclusion was correct, but we question the simple explanation that national intelligence causes national wealth. We argue that the relationship is more complex.' (Hunt \& Wittman, 2008 p. 1). In addition, studies have also shown that intelligence is robustly related to shadow economy (Salahodjaev, 2015a), financial development (Salahodjaev, 2015b), corruption (Potrafke, 2012), sustainability (Salahodjaev, 2016a) and deforestation (2016b)

To mitigate the potential omitted variable bias, we include a vector of bio-geography control variables. Masters \& MacMillan (2001) explore the role of geography and climate in convergence of income across the globe. They have found that countries in temperate climate zones have had more rapid growth rates of GDP per capita. On the other hand, larger share of population in tropics was a barrier to economic growth. Olsson and Hibbs (2005 p. 909) provide 'evidence from a large cross-section of countries indicates that the effects of geography and biogeography on contemporary levels of economic development are remarkably strong, a result that contrasts with several recent studies where the effect runs solely through institutions'. Therefore, we control for the latitude, share of population living in tropics and logged land size. The data is from Ashraf and Galor (2013).

The statistical model of interest can be specified as following:

$$
Y_{i}=\alpha_{0}+\alpha_{1} I N D_{i}+\alpha_{2} I Q_{i}+\alpha_{3} \text { Latitude }_{i}+\alpha_{4} \text { Tropics }_{i}+\alpha_{5} \text { Land }_{i}+\varepsilon_{i}
$$

where $\mathrm{Y}$ is logged GDP per capita at PPP in each country; IND is Individualism index; IQ is the average national intelligence; Latitude refers to geographic latitude; Tropics refers to the share of population living in the tropics, Land refers to logged land area and e represents an error term satisfying normality assumption. We estimate equation 1 using Ordinary Least Squares (OLS) regression estimator. The descriptive statistics and correlation matrix are presented in Tables 1 and 2. The correlation matrix suggests that both national IQs and individualism are positively correlated with logged GDP per capita. On the other hand, correlation coefficients between land size, share of population living in tropics and logged GDP per capita are negative.

Table 1. Descriptive statistics

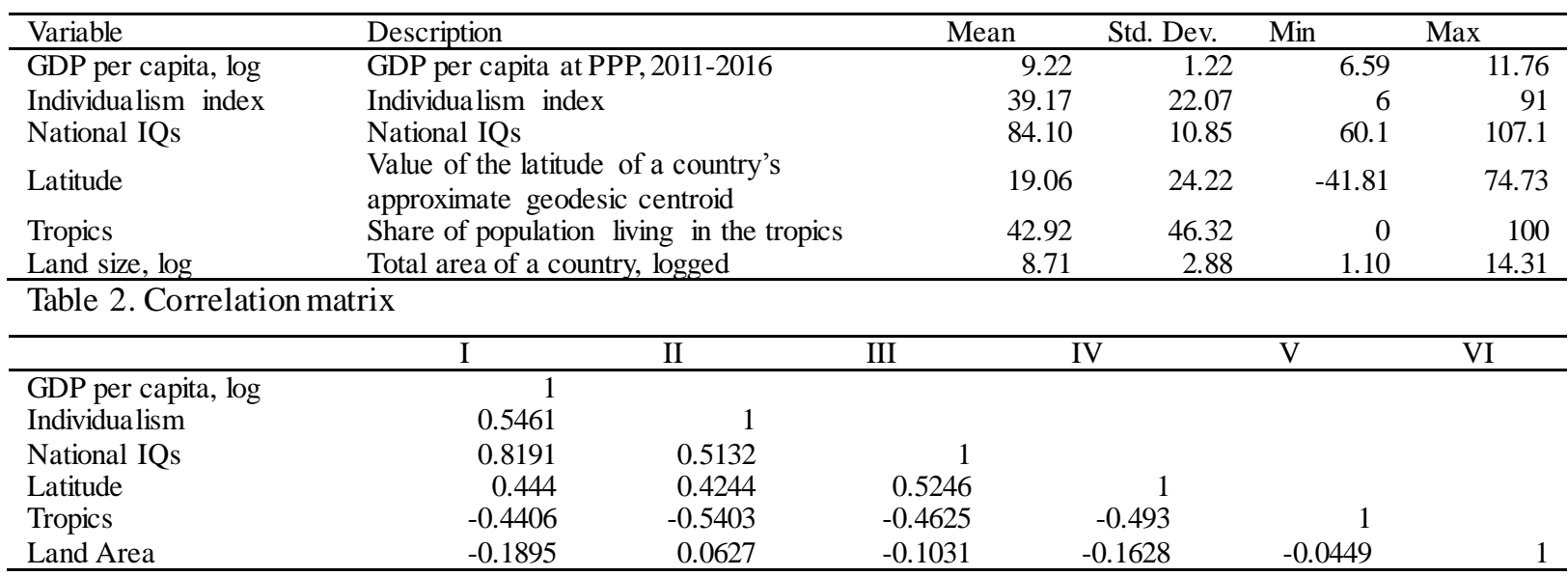

\section{Results}

Key results are displayed in Table 3. Column 1 offers a simple regression model with logged GDP per capita as dependent variable and individualism index as sole predictor. In line with past studies, individualism is positive and significant at the $1 \%$ level. The results suggest that one point increase in individualism index is associated with nearly $2.6 \%$ increase in GDP per capita. In this model, individualism explains approximately $29 \%$ of economic development across the sample of 97 countries.

Next, in column 2 we include national IQs as a proxy for intelligence from Lynn and Vanhanen (2012). The results, replicate Lynn and Vanhanen (2012) study showing that intelligence is positively related with economic development. In particular, a one point increase in national IQs is associated with nearly $7.5 \%$ increase in GDP per capita. Turning to our main variable of interest, the effect of individualism and its significance have substantially decreased. This indicates that the effect of individualism on economic development is largely mediated by cognitive capital. One potential explanation is that intelligence is instrumental to efficient institutions (Kanyama, 2014) and democracy (Vanhanen, 2002).

Column 3 further includes biogeography variables that may be correlated with intelligence, individualism and economic development: latitude, share of population living in the tropics and logged land size. Among these 
variables, only land size is negative and significant at the $5 \%$ level. Both individualism and intelligence is quantitatively and qualitatively unaffected.

However, one may argue that cross-section data does not take into account unobserved heterogeneity of our sample. Therefore, to partially resolve this issue we include continental dummies to capture geographical differences in column 4. Even after controlling for a set of regional dummies intelligence and individualism is positive and significant at the $1 \%$ level. This model explains approximately $72 \%$ of cross-national variations in GDP per capita.

Table 3. Individualism, IQ and economic development

Main Results

\begin{tabular}{|c|c|c|c|c|}
\hline & (1) & (2) & (3) & (4) \\
\hline \multirow[t]{2}{*}{ Individua lism } & $0.026 * * *$ & $0.008 * *$ & $0.009 * *$ & $0.011 * * *$ \\
\hline & $(0.004)$ & $(0.003)$ & $(0.003)$ & $(0.004)$ \\
\hline \multirow[t]{2}{*}{ IQ } & & $0.072 * * *$ & $0.071 * * *$ & $0.058 * * *$ \\
\hline & & $(0.007)$ & $(0.007)$ & $(0.010)$ \\
\hline \multirow[t]{2}{*}{ Latitude } & & & -0.002 & -0.003 \\
\hline & & & (0.003) & (0.005) \\
\hline \multirow[t]{2}{*}{ Tropics } & & & -0.001 & $-0.003^{*}$ \\
\hline & & & $(0.002)$ & $(0.002)$ \\
\hline \multirow[t]{2}{*}{ Land size $(\log )$} & & & $-0.070 * *$ & $-0.076 * *$ \\
\hline & & & $(0.030)$ & $(0.031)$ \\
\hline \multirow[t]{2}{*}{ Africa } & & & & $-0.772 * * *$ \\
\hline & & & & $(0.272)$ \\
\hline Asia & & & & -0.306 \\
\hline \multirow{2}{*}{ Europe } & & & & 0368 \\
\hline & & & & $(0.257)$ \\
\hline \multirow[t]{2}{*}{ Oceania } & & & & -0.601 \\
\hline & & & & $(0.466)$ \\
\hline \multirow[t]{2}{*}{ South America } & & & & -0.076 \\
\hline & & & & $(0.315)$ \\
\hline \multirow[t]{2}{*}{ Constant } & $8.649 * * *$ & $2.964 * * *$ & $3.816 * * *$ & $5.453 * * *$ \\
\hline & $(0.183)$ & $(0.532)$ & $(0.699)$ & $(0.909)$ \\
\hline$N$ & 97 & 97 & 97 & 97 \\
\hline adj. $R^{2}$ & 0.291 & 0.686 & 0.695 & 0.716 \\
\hline
\end{tabular}

Standard errors in parentheses

$* \mathrm{p}<0.1, * * \mathrm{p}<0.05, * * * \mathrm{p}<0.01$

Table 4. Individualism, IQ and economic development

Regional Differences

\begin{tabular}{|c|c|c|c|c|}
\hline & $\begin{array}{l}\text { (1) } \\
\text { All }\end{array}$ & $\begin{array}{c}\text { (2) } \\
\text { No Latin America }\end{array}$ & $\begin{array}{c}\text { (3) } \\
\text { No Africa }\end{array}$ & $\begin{array}{c}\text { (4) } \\
\text { No Europe }\end{array}$ \\
\hline Individualism & $\begin{array}{l}0.0089 * * \\
(0.0035)\end{array}$ & $\begin{array}{c}0.0108 * * * \\
(0.0037)\end{array}$ & $\begin{array}{c}0.0093 * * * \\
(0.0035)\end{array}$ & $\begin{array}{l}0.0095^{*} \\
(0.0055)\end{array}$ \\
\hline IQ & $\begin{array}{l}0.0711 * * * \\
(0.0072)\end{array}$ & $\begin{array}{c}0.0678 * * * \\
(0.0079)\end{array}$ & $\begin{array}{c}0.0505^{* * * *} \\
(0.0100)\end{array}$ & $\begin{array}{c}0.0728 * * * \\
(0.0086)\end{array}$ \\
\hline Latitude & $\begin{array}{l}-0.0022 \\
(0.0029)\end{array}$ & $\begin{array}{l}-0.0016 \\
(0.0037)\end{array}$ & $\begin{array}{l}-0.0018 \\
(0.0030)\end{array}$ & $\begin{array}{l}-0.0014 \\
(0.0041)\end{array}$ \\
\hline Tropics & $\begin{array}{l}-0.0010 \\
(0.0018)\end{array}$ & $\begin{array}{l}-0.0026 \\
(0.0022)\end{array}$ & $\begin{array}{l}-0.0016 \\
(0.0020)\end{array}$ & $\begin{array}{l}-0.0012 \\
(0.0023)\end{array}$ \\
\hline Land area, log & $\begin{array}{c}-0.0703 * * \\
(0.0297)\end{array}$ & $\begin{array}{c}-0.0874 * * * \\
(0.0323)\end{array}$ & $\begin{array}{c}-0.0713 * * \\
(0.0301)\end{array}$ & $\begin{array}{c}-0.0784 * \\
(0.0429)\end{array}$ \\
\hline Constant & $\begin{array}{c}3.8159 * * * \\
(0.6991)\end{array}$ & $\begin{array}{c}4.1687 * * * \\
(0.7528)\end{array}$ & $\begin{array}{c}5.7440 * * * \\
(0.9673)\end{array}$ & $\begin{array}{c}3.7544 * * * \\
(0.8735)\end{array}$ \\
\hline $\begin{array}{l}N \\
\text { adj. } R^{2}\end{array}$ & $\begin{array}{c}97 \\
0.6947\end{array}$ & $\begin{array}{c}82 \\
0.7223\end{array}$ & $\begin{array}{c}80 \\
0.5064\end{array}$ & $\begin{array}{c}64 \\
0.6067\end{array}$ \\
\hline
\end{tabular}

Standard errors in parentheses

$* \mathrm{p}<0.1, * * \mathrm{p}<0.05, * * * \mathrm{p}<0.01$

Finally, in Table 4 we test whether the effect of individualism and intelligence differ by region. In column 2 we removed Latin American countries. The estimate for intelligence has decreased suggesting that cognitive skills may be the driver of economic growth in this region. On the other hand, the estimate for individualism has slightly increased, indicating that culture may have played minor role of in fostering economic development. Indeed, individualism scores are below 50 points for this sample, suggesting that Latin America is rather collectivistic society (Table 5). For example, individualism index for Guatemala is only 6 points. In column 3 we 
removed African countries. Both intelligence and individualism retains significance at the $1 \%$ levels. In column 4 European countries were excluded from our sample. While the estimate for individualism is only significant at the $10 \%$ level, the effect of intelligence remains robust. One reason for the reduction of individualism may be that Europe is considered individualistic society, and makes up largest share of our sample.

Table 5. Summary data

Latin America

\begin{tabular}{|c|c|c|c|}
\hline Country & GDP per capita, 2011-2016 & IQ & Individualism \\
\hline Argentina & 19907.2 & 92.8 & 46 \\
\hline Bolivia & 6442.4 & 87 & \\
\hline Brazil & 15545.5 & 85.6 & 38 \\
\hline Chile & 22543.1 & 89.8 & 23 \\
\hline Colombia & 12943.1 & 83.1 & 13 \\
\hline Costa Rica & 14951.6 & 89 & 15 \\
\hline Cuba & & 85 & \\
\hline Dominica & 10558.6 & 67 & \\
\hline Dominican Republic & 13014.2 & 82 & 30 \\
\hline Ecuador & 10957.2 & 88 & 8 \\
\hline El Salvador & 8015.4 & 78 & 19 \\
\hline Guatemala & 7393.4 & 79 & 6 \\
\hline Haiti & 1691.0 & 67 & \\
\hline Honduras & 4394.7 & 81 & 20 \\
\hline Mexico & 16922.1 & 87.8 & 30 \\
\hline Nicaragua & 4901.7 & 84 & \\
\hline Panama & 20190.1 & 80 & 11 \\
\hline Paraguay & 8532.7 & 84 & \\
\hline Peru & 11856.1 & 84.2 & 16 \\
\hline Puerto Rico & 34497.2 & 83.5 & \\
\hline Uruguay & 20048.6 & 90.6 & 36 \\
\hline Venezuela, RB & 17755.7 & 83.5 & 12 \\
\hline $\begin{array}{l}\text { As a final robust test } \\
\text { bio-geography variables } \\
\text { share of population that } \\
\text { index and share of land } \\
9 \text { control variables. The } \\
\text { However, the results of } \\
\text { ration for IQ exceeds for }\end{array}$ & $\begin{array}{l}\text { nodel robustness and mod } \\
\text { led for population size in } 140 \\
\text { d area, share of population } \\
\text { a result we have estimated } \\
\text { both individualism and IQs } \\
\text { s suggest that IQ does over } \\
\text { ompared to } 2.7 \text { ). }\end{array}$ & $\begin{array}{l}\text { uence } \\
\text { re of pop } \\
\text { ean desc } \\
\text { gression } \\
\text { gnificant } \\
\text { individua }\end{array}$ & $\begin{array}{l}\text { wider range of } \\
\text { living in tropics, } \\
\text { rrain ruggedness } \\
\text { cation with up to } \\
\% \text { of regression. } \\
\text { s the robustness }\end{array}$ \\
\hline
\end{tabular}

\section{Discussion}

Over the past decade the differences in the levels of economic development have remained dramatic across developed and developing countries. As a result, the causes of economic wealth have attracted significant research interest. In this study, we explored the role of culture measured by individualistic values and intelligence levels in explaining cross-national differences in GDP per capita.

Past research has shown that intelligence, measured by national IQs, is significantly and positively correlated with GDP per capita. For example, Lynn and Vanhanen (2002) show that the correlation between cognitive abilities and GDP per capita is .66. In a follow up study, Dickerson (2006) using data from 185 countries shows that the correlation between cognitive abilities and economic development is .67 .

A separate strand of literature has shown that individualism is robustly associated with economic growth and levels of GDP per capita. Gorodnichenko and Roland (2016) using data for more than 96 countries, and instrumenting individualism with Mahalanobis distance of frequency of blood types A and B in a given country relative to the frequency of blood types Aand B in the UK, show that individualism has causal effect on logged GDP per capita.

The goal of this study is to bridge to strands of literature. Particularly, we tested whether intelligence and individualism remains significant predictors of economic development once we control for these two factors together.

Our results show that both intelligence and individualistic values increase economic development even when we take into account the role of bio-geography. In particular, a one point increase in national IQs is associated with nearly $7.5 \%$ increase in GDP per capita. The results remain robust even when we check the effect of regional differences on economic development.

\section{References}

Ball, R. (2001). Individualism, collectivism, and economic development. The Annals of the American Academy 
of Political and Social Science, 573(1), 57-84. https://doi.org/10.1177/000271620157300104

Dickerson, R. E. (2006). Exponential correlation of IQ and the wealth of nations. Intelligence, 34, 292-295. https://doi.org/10.1016/j.intell.2005.09.006

Gorodnichenko, Y., \& Roland, G. (2011). Individualism, innovation, and long-run growth. Proceedings of the National Academy of Sciences, 108(Supplement 4), 21316-21319. https://doi.org/10.1073/pnas.1101933108

Gorodnichenko, Y., \& Roland, G. (2016). Culture, institutions and the wealth of nations. Review of Economics and Statistics, (0).

Gottfredson, L. S. (1997). Why g matters: The complexity of everyday life. Intelligence, 24(1), 79-132. https://doi.org/10.1016/S0160-2896(97)90014-3

Hofstede, G. (1980). Culture's consequences: National differences in thinking and organizing. Beverly Hills, Calif.: Sage.

Hunt, E., \& Wittmann, W. (2008). National intelligence and national prosperity. Intelligence, 36(1), 1-9. https://doi.org/10.1016/j.intell.2006.11.002

Jones, G., \& Schneider, W. J. (2006). Intelligence, human capital, and economic growth: A Bayesian averaging of classical estimates (BACE) approach. Journal of economic growth,11(1), 71-93. https://doi.org/10.1007/s10887-006-7407-2

Lynn, R., \& Vanhanen, T. (2002). IQ and the wealth of nations. Westport, CT: Praeger Publishers.

Lynn, R., \& Vanhanen, T. (2012). Intelligence. A unifying construct for the social sciences. London: Ulster Institute for Social Research.

Masters, W. A., \& McMillan, M. S. (2001). Climate and scale in economic growth. Journal of Economic Growth, 6(3), 167-186. https://doi.org/10.1023/A:1011398431524

Nikolaev, B., \& Salahodjaev, R. (2017). Historical prevalence of infectious diseases, cultural values, and the origins of economic institutions. Kyklos, 70(1), 97-128. https://doi.org/10.1111/kykl.12132

Olsson, O., \& Hibbs, D. A. (2005). Biogeography and long-run economic development. European Economic Review, 49(4), 909-938. https://doi.org/10.1016/j.euroecorev.2003.08.010

Papamarcos, S. D., \& Watson, G. W. (2006). Culture's consequences for economic development: an empirical examination of culture, freedom, and national market performance. Journal of Global business and Technology, 2(1), 48-57.

Potrafke, N. (2012). Intelligence and corruption. Economics Letters, 114(1), 109-112. https://doi.org/10.1016/j.econlet.2011.09.040

Ram, R. (2007). IQ and economic growth: Further augmentation of Mankiw-Romer-Weil model. Economics Letters, 94(1), 7-11. https://doi.org/10.1016/j.econlet.2006.05.005

Salahodjaev, R. (2015a). Intelligence and shadow economy: A cross-country empirical assessment. Intelligence, 49, 129-133. https://doi.org/10.1016/j.intell.2015.01.010

Salahodjaev, R. (2015b). Intelligence and finance. Personality and Individual Differences, 86, 282-286. https://doi.org/10.1016/j.paid.2015.06.017

Salahodjaev, R. (2016a). Does intelligence improve environmental sustainability? An empirical test. Sustainable Development, 24(1), 32-40. https://doi.org/10.1002/sd.1604

Salahodjaev, R. (2016b). Intelligence and deforestation: International data. Forest Policy and Economics, 63, 20-27. https://doi.org/10.1016/j.forpol.2015.12.003

Stolarski, M., Jasielska, D., \& Zajenkowski, M. (2015). Are all smart nations happier? Country aggregate IQ predicts happiness, but the relationship is moderated by individualism-collectivism. Intelligence, 50, 153-158. https://doi.org/10.1016/j.intell.2015.04.003

\section{Copyrights}

Copyright for this article is retained by the author(s), with first publication rights granted to the journal.

This is an open-access article distributed under the terms and conditions of the Creative Commons Attribution license (http://creativecommons.org/licenses/by/4.0/). 